\title{
Estudio bacteriológico de la orina previa a la cirugía urológica endoscópica
}

\author{
V. Menéndez López, J. Antonio Galán Llopis, M. Elía López*, C. Carro Rubias, A. Collado Serra**, \\ L. de Paz Cruz, F. García López
}

Servicio de Urología. Hospital General Universitario de Elche. Alicante. *Servicio de Microbiología. Hospital General de Elda. Alicante. **Servicio de Urología. Instituto Valenciano de Oncología. Valencia.

Actas Urol Esp 2005; 29 (7): 667-675

\section{RESUMEN}

ESTUDIO BACTERIOLÓGICO DE LA ORINA PREVIA A LA CIRUGÍA UROLÓGICA ENDOSCÓPICA

Objetivo: Los objetivos de este estudio son conocer la incidencia de bacteriuria preoperatoria en pacientes que van a ser sometidos a intervenciones urológicas por vía endoscópica, analizar los microorganismos más frecuentes que aparecen en los cultivos y sus resistencias a los antibióticos, para así seleccionar el antibiótico profiláctico más apropiado para nuestra población y determinar qué factores de riesgo están relacionados con la aparición de bacteriuria o sepsis urinaria en el postoperatorio.

Material y Método: Se incluyeron en el estudio a 449 pacientes a los que se les iba a someter a cirugía urológica endoscópica. Se recogieron muestras de orina para su cultivo antes de la administración del antibiótico profiláctico y se volvieron a tomar a la semana de retirar la sonda vesical, ya sin tratamiento antibiótico. Se analizaron las variables que podían estar relacionadas con la mayor incidencia de complicaciones infecciosas. Se prestó especial atención a las incidencias del postoperatorio, y sobre todo, a las de naturaleza infecciosa.

Resultados: Se detectó bacteriuria preoperatoria en 66 de 428 pacientes (15,4\%). Esta se asoció a la edad, el sexo, la historia de infecciones previas, la existencia de diabetes mellitus, la presencia de sonda vesical y a la patología que indicaba la intervención quirúrgica. El tipo de microorganismo más frecuente fue Escherichia coli $(43,1 \%)$. En el 37,9\% de los pacientes con bacteriuria preoperatoria el microorganismo fue resistente al antibiótico utilizado profilácticamente para la intervención quirúrgica. Apareció bacteriuria postoperatoria en el $22 \%$ de los pacientes, lo que se asoció únicamente a la presencia de bacteriuria preoperatoria. El 2,9\% de los pacientes tuvieron criterios de sepsis de origen urinario durante la estancia hospitalaria. La sepsis se asoció únicamente a la duración de la cirugía y no a la presencia de bacteriuria preoperatoria, ni con los días de permanencia de la sonda, y ni a la utilización, en estos casos, de un antibiótico profiláctico "no apropiado".

Conclusión: Una parte importante de los pacientes sometidos a cirugía endoscópica presentan bacteriuria preoperatoria, aunque fue responsable de la bacteriuria posoperatoria en menos del $25 \%$ de los casos. La duración de la cirugía parece ser la única causa relacionada con la sepsis de origen urinario.

Palabras clave: Cirugía endoscópica. Bacteriuria. Sepsis urinaria. Profilaxis antibiótica.

\section{ABSTRACT}

\section{URINARY BACTERIOLOGIC STUDY PRIOR TO ENDOSCOPIC UROLOGIC SURGERY}

Objective: The objectives of this study are to know the incidence of preoperative bacteriuria in patients undergoing endoscopic urologic surgery, to analyze the most frequent microorganisms appearing in the cultures and their resistance to antibiotics in order to select the most appropriate prophylactic one for our population, and to determine the risk factors related to postoperative bacteriuria or sepsis of urologic origin.

Material and Methods: 449 patients undergoing endoscopic urologic surgery were included in the study. Urinary samples were collected for culture prior to prophylactic antibiotic administration and again a week after bladder catheter removal once the antibiotic treatment was finished. Variables related to an increase in infectious complications were analyzed. Special attention was paid to postoperatory incidences, mainly those of infectious nature.

Results: Preoperative bacteriuria was found in 66 out of 428 patients (15.4\%). It was found to be related to age, sex, previous infection episodes, diabetes mellitus, indwelling catheter and to the pathology for which operation was indicated. The most frequently found microorganism was Escherichia Coli. Resistance to prophylactic antibiotic was found in $37.9 \%$ of patients with preoperatory bacteriuria. Postoperatory bacteriuria, observed in $22.0 \%$ of the patients was exclusively related to preoperatory bacteriuria. $2.9 \%$ of patients showed sepsis of urinary origin criteria during hospital staying, and it was found to be exclusively related to length of surgery and neither to preoperatory bacteriuria nor to indwelling catheter time or the "inappropriate" prophylactic antibiotic use in these cases.

Conclusions: A good part of patients who underwent endoscopic surgery showed preoperatory bacteriuria, responsible for postoperative bacteriuria in less than $25 \%$ of the cases. The length of surgery seemed to be the only related cause whit sepsis of urinary origin.

Keywords: Endoscopic surgery. Bacteriuria. Urinary sepsis. Antibiotic prophylaxis. 
$\mathrm{L}$ a cirugía endoscópica es hoy en día uno de los procedimientos más habituales en la práctica urológica. Las infecciones urinarias representan una de las complicaciones más frecuentes ${ }^{1}$ y la resección transuretral de la próstata (RTUP) ha sido clasificada como una cirugía contaminada, con un riesgo de infección del $20 \%{ }^{2}$. Históricamente, la utilización de antibióticos profilácticos se rechazaba basándose en que las cirugías limpias contaminadas no precisaban cobertura antibiótica $^{3-5}$. En contrapartida, también se ha demostrado que la manipulación del tracto urinario es la principal causa de infecciones urinarias y bacteriemia ${ }^{6}$. Con el paso del tiempo han ido proliferando los estudios que demuestran que la utilización de antibióticos profilácticos en dosis única disminuye el número de complicaciones infecciosas $^{3,7-8}$, aunque hay autores que defienden la utilización de pautas cortas de antibióticos, normalmente durante 2 ó 3 días o hasta la retirada de la sonda ${ }^{9-15}$. La mejora de las técnicas quirúrgicas, la utilización de circuitos cerrados para el drenaje de la orina y la precoz retirada de la sonda disminuyen la tasa de complicaciones infecciosas.

\section{MATERIAL Y MÉTODOS}

Para la realización de este estudio se incluyeron aquellos pacientes mayores de 18 años y de ambos sexos que ingresaron para ser intervenidos de cirugía urológica endoscópica en nuestro hospital. Se excluyeron aquellos que habian estado ingresados más de 24 horas antes de la intervención o que se preveía que por alguna razón deberían permanecer ingresados más tiempo del habitual, así como aquellos que estaban tomando antibióticos inmediatamente antes de la cirugía o padecían enfermedades que obligaban a una pauta específica de antibióticos (p.e. endocarditis). Tampoco entraron en el estudio aquellos enfermos que presentaban alguna patología que pudiera comprometer su estado inmunitario o aquellos en los que se preveía que pudieran precisar sonda en el postoperatorio durante un periodo de tiempo superior a una semana.

Se realizó a todos los pacientes un cultivo de orina, procedente de la parte media de la micción previo lavado de los genitales externos con detergente sin antiséptico, la cual se recogió en un recipiente estéril tanto al ingreso como a la semana de la retirada de la sonda. En los pacientes portadores de sonda vesical, la orina se obtuvo a través de la misma, desechando el primer chorro. $\mathrm{Al}$ inicio del estudio el tratamiento antibiótico profiláctico se realizó con cefazolina ( $1 \mathrm{~g}$ vía EV 1 hora antes de la cirugía seguido por $500 \mathrm{mg} / 12 \mathrm{~h}$ vía IM hasta retirada de la sonda) dado que era el recomendado por el Comité de Infecciones de nuestro hospital, sustituyéndose posteriormente por ciprofloxacino o amoxicilina/clavulánico. En todos los casos se administró una dosis una hora antes de la intervención quirúrgica (ciprofloxacino $200 \mathrm{mg}$ por vía endovenosa; amoxicilina/clavulánico $1.000 / 200 \mathrm{mg}$ por vía endovenosa), cambiando posteriormente a pauta por vía oral hasta el día de la retirada de la sonda (ciprofloxacino 500 mg cada 12 horas; amoxicilina/clavulánico 875/125 mg cada 12 horas).

Las variables analizadas fueron: sexo, edad, infecciones urinarias previas, enfermedades crónicas como diabetes, presencia de sonda uretral antes de la cirugía, tipo de intervención quirúrgica, duración de la intervención quirúrgica, cirujano, tiempo de permanencia de la sonda tras la cirugía, así como la aparición de fiebre durante el periodo en que permanecieron ingresados o tras el alta hospitalaria. Los datos clínicos y de seguimiento de los pacientes se obtuvieron de la historia clínica y de la entrevista con el paciente durante la primera visita postoperatoria.

El urocultivo se consideró positivo si se aislaban $\geq 10^{3} \mathrm{ufc} / \mathrm{ml}$ de un microorganismo en cultivo puro, aunque en más del $80 \%$ de los casos el microorganismo se aisló en recuentos $\geq 10^{5}$ ufc/ml. No obstante, en mujeres con disuria y síndrome uretral, recuentos inferiores a $10^{3}$ $\mathrm{ufc} / \mathrm{ml}$ se consideraron positivos.

Las variables epidemiológicas fueron estudiadas mediante análisis descriptivo. La comparación entre dos variables cualitativas se realizó mediante el test de chi-cuadrado, mientras que se utilizó el test T de Student para comprobar la relación entre variables cuantitativas y cualitativas. El nivel de significación se fijó en $\mathrm{p}<0,05$ bilateral. 


\section{RESULTADOS}

Se incluyeron un total de 449 pacientes, de los cuales fueron eliminados $21(4,7 \%)$ por tener el cultivo de orina previo a la cirugía contaminado. 428 pacientes fueron utilizados para conocer la incidencia de bacteriuria preoperatoria y seleccionar el antibiótico profiláctico más adecuado para nuestro grupo de pacientes.

De los 428 pacientes, se detectó bacteriuria preoperatoria en $66(15,4 \%)$. Esta se asoció a la edad, el sexo, la historia de infecciones previas, la existencia de diabetes mellitus, la presencia de sonda vesical y el tipo de patología que indicaba la intervención quirúrgica (Tabla 1). De los 66 pacientes con cultivos preoperatorios positivos, en 7 se detectó más de un microorganismo (10,6\%). El tipo de microorganismo más frecuente fue Escherichia coli $(43,1 \%)$. De los 71 microorganismos detectados, en 31 (43\%) el antibiótico utilizado para la profilaxis no fue el apropiado. Esto significa que en el $37,9 \%$ de los pacientes con bacteriuria preoperatoria el microorganismo fue resistente al antibiótico utilizado profilácticamente (Tabla 2). En la Tabla 3 se reflejan las sensibilidades a los antibióticos de los microorganismos hallados en este estudio.

Tabla 1

Factores asociados a la presencia de bacteriuria preoperatoria

\begin{tabular}{lccc}
\hline Característica & $\begin{array}{c}\text { Orina estéril } \\
\boldsymbol{n}(\%)\end{array}$ & $\begin{array}{c}\text { Bacteriuria } \\
\boldsymbol{n}(\%)\end{array}$ & $\boldsymbol{p}$ \\
\hline Sexo & & & \\
$\quad$ Hombre & $341(85,9)$ & $56(14,1)$ & $<0,05$ \\
$\quad$ Mujer & $21(67,7)$ & $10(32,3)$ & \\
Infecciones urinarias previas & & & \\
$\quad$ No & $312(87,4)$ & $45(12,6)$ & $<0,01$ \\
$\quad$ Sí & $50(70,4)$ & $21(26,9)$ & \\
Diabetes mellitus & & & \\
$\quad$ No & $333(85,8)$ & $55(14,2)$ & $<0,05$ \\
$\quad$ Sí & $29(72,5)$ & $11(27,5)$ & \\
Portador sonda vesical & & & \\
$\quad$ No & $349(90,2)$ & $38(9,8)$ & $<0,01$ \\
$\quad$ Si & $13(31,7)$ & $28(68,3)$ & \\
Patología urológica & & & \\
$\quad$ Tumor vesical & $190(93,1)$ & $14(6,9)$ & $<0,01$ \\
$\quad$ HBP & $109(75,2)$ & $36(24,8)$ & \\
Litiasis vesical & $29(80,6)$ & $7(19,4)$ & \\
Tumor vesical +HBP & $13(81,3)$ & $3(18,8)$ & \\
Patología uretral & $13(92,9)$ & $1(7,1)$ & \\
Patología ureteral & $8(61,5)$ & $5(38,5)$ & \\
Edad (media \pm DS) & $66,5 \pm 10,3$ & $69,3 \pm 10,7$ & $<0,05$ \\
\hline
\end{tabular}

HBP: Hipertrofia benigna de próstata DS: Desviación estándar
Para determinar los factores de riesgo que estaban relacionados con la aparición de bacteriuria o sepsis urinaria en el postoperatorio tuvimos que eliminar $2(0,5 \%)$ pacientes por suspensión quirúrgica, $12(2,8 \%)$ por incidencias asociadas a la cirugía, $49(11,4 \%)$ por cultivo postoperatorio no realizado y $20(4,7 \%)$ por cultivo postoperatorio contaminado. Tras esto, se consideraron válidos para esta sección del estudio a 345 pacientes.

Apareció bacteriuria postoperatoria en 76 $(22 \%)$ pacientes. Ello se asoció únicamente a la presencia de bacteriuria preoperatoria (Tabla 4). En estos 76 pacientes, 22 tenían el cultivo previo positivo pero en 9 el microorganismo era distinto. De los 13 pacientes con cultivos preoperatorios y postoperatorios positivos y con coincidencia de microorganismo, en 8 pacientes el microorganismo era sensible al antibiótico utilizado para la profilaxis preoperatoria. La distribución de los microorganismos observados en las bacteriurias postoperatoria se describe en la Tabla 5.

De los 345 pacientes, 10 (2,9\%) tuvieron criterios de sepsis de origen urinario durante la estancia hospitalaria y $7(2 \%)$ en el periodo comprendido entre el alta hospitalaria y la primera visita. Un paciente presentó estos criterios tanto durante el ingreso como tras el alta hospitalaria.

La sepsis se asoció únicamente a la duración de la cirugía y no, como cabría esperar, a la presencia de bacteriuria preoperatoria, a los días de permanencia de la sonda y a la utilización de un antibiótico profiláctico "no apropiado".

\section{DISCUSIÓN}

La tasa de bacteriuria preoperatoria oscila en las series revisadas entre el $3,5 \%{ }^{12}$ y el $11,7 \%{ }^{15}$, aunque en una serie de 2.223 resecciones prostáticas publicada por Melchior ${ }^{16}$ en 1974 presenta un $23 \%$ de los cultivos preoperatorios positivos. Nuestra tasa de bacteriuria preoperatoria, con un $15,4 \%$, está por encima de lo esperado según la experiencia de otros autores, y más teniendo en cuenta que la 
Tabla 2

Distribución y características de los microorganismos hallados en los pacientes con bacteriuria preoperatoria

\begin{tabular}{|c|c|}
\hline Microorganismo & № de casos (\%) \\
\hline Escherichia coli & $31(43,1)$ \\
\hline Enterococcus faecalis & $14(19,4)$ \\
\hline Staphylococcus epidermidis & $7(9,7)$ \\
\hline Enterobacter cloacae & $5(6,9)$ \\
\hline Klebsiella pneumoniae & $4(5,6)$ \\
\hline Streptococcus $s p$ & $2(2,8)$ \\
\hline Alcaligenes $s p$ & $1(1,4)$ \\
\hline Citrobacter koserii & $1(1,4)$ \\
\hline Enterococcus faecium & $1(1,4)$ \\
\hline Klebsiella oxytoca & $1(1,4)$ \\
\hline Morganella morganii & $1(1,4)$ \\
\hline Proteus mirabilis & $1(1,4)$ \\
\hline Pseudomona aeruginosa & $1(1,4)$ \\
\hline Serratia liquefaciens & $1(1,4)$ \\
\hline Serratia marcescens & $1(1,4)$ \\
\hline \multicolumn{2}{|l|}{ Familias bacterianas } \\
\hline Enterobacterias & $47(65,3)$ \\
\hline Estreptococos - Enterococos & $17(23,6)$ \\
\hline Estafilococos & $7(9,7)$ \\
\hline Pseudomonas & $1(1,4)$ \\
\hline \multicolumn{2}{|l|}{ Clasificación de Gram } \\
\hline Negativo & $48(66,7)$ \\
\hline Positivo & $24(33,3)$ \\
\hline \multicolumn{2}{|l|}{$\begin{array}{l}\text { Sensibilidad al antibiótico } \\
\text { profiláctico }\end{array}$} \\
\hline Sensible & $41(56,9)$ \\
\hline Resistente & $31(43,1)$ \\
\hline
\end{tabular}

Tabla 3

Resistencias bacterianas a los antibióticos profilácticos utilizados

\begin{tabular}{lccc}
\hline & $\begin{array}{c}\text { Sensible } \\
\mathbf{n}(\%)\end{array}$ & $\begin{array}{c}\text { Intermedio } \\
\mathbf{n ~ ( \% )}\end{array}$ & $\begin{array}{c}\text { Resistente } \\
\mathbf{n}(\%)\end{array}$ \\
\hline $\begin{array}{l}\text { Preoperatorio } \\
\quad \text { Amoxicilina/clavulánico } \\
\text { Cefazolina }\end{array}$ & $36(66,6)$ & $2(3,7)$ & $16(29,6)$ \\
Ciprofloxacino & $3(42,9)$ & - & $4(57,1)$ \\
Postoperatorio & $2(18,2)$ & - & $9(81,8)$ \\
Amoxicilina/clavulánico & $29(46,0)$ & $4(6,3)$ & $30(47,7)$ \\
Cefazolina & $5(41,7)$ & - & $7(58,3)$ \\
Ciprofloxacino & $3(12,5)$ & - & $21(87,5)$ \\
Global & & - & $46(39,3)$ \\
Amoxicilina/clavulánico & $65(55,6)$ & $6(5,1)$ & $11(57,9)$ \\
Cefazolina & $8(42,1)$ & - & $30(85,7)$ \\
Ciprofloxacino & $5(14,3)$ & - & \\
\hline
\end{tabular}

mayor parte de los trabajos se limitan a estudiar pacientes que van a ser intervenidos de próstata y son el grupo en los que más bacteriuria se detecta.

La relación entre la bacteriuria y la infección urinaria es variable $e^{15}$ y su importancia es difícil de valorar. Hay trabajos que analizan la orina a las 24 h de la cirugía y en estos casos la bacteriuria parece tener poca importancia, aunque con el paso del tiempo se correlaciona con la sintomatología de la infección $^{12}$.

Los pacientes sometidos a cirugía endoscópica con bacteriuria previa tienen un riesgo de sufrir complicaciones infecciosas postoperatorias siete veces mayor que aquellos con cultivos de orina negati$\operatorname{vos}^{17}$. La incidencia de hemorragia a los 7-10 días tras la RTUP y la esclerosis del cuello aumentan de forma importante si existe bacteriuria $^{15}$.

El único factor preoperatorio reversible del sangrado post-RTU es la corrección de la infección urinaria preoperatoria $^{18}$. Es por este motivo que Schaeffer recomienda descartar la presencia de bacteriuria mediante cultivo antes de la cirugía ${ }^{19}$.

Los cultivos de orina realizados en el preoperatorio estaban relacionados de forma significativa con la edad, el sexo, la existencia de infecciones de orina previas, la presencia de diabetes mellitus, el tipo de patología que indicaba la cirugía y la presencia de sonda vesical. No hemos encontrado diferencias en cuanto al tipo de microorganismo detectado en la orina de este último grupo de enfermos respecto al total.

El microorganismo más frecuentemente detectado fue Eschericia 
Tabla 4

Relación entre la bacteriuria preoperatoria y postoperatoria

\begin{tabular}{|c|c|c|c|c|}
\hline & \multicolumn{3}{|c|}{ Bacteriuria postoperatoria } & \multirow[t]{2}{*}{$\mathbf{p}$} \\
\hline & & $\begin{array}{c}\text { No } \\
\text { n (\%) }\end{array}$ & $\begin{array}{c}\text { Sí } \\
\text { n (\%) }\end{array}$ & \\
\hline \multirow[t]{2}{*}{ Bacteriuria preoperatoria } & No & $246(82,0)$ & $54(18,0)$ & $<0,01$ \\
\hline & $\mathrm{Si}$ & $23(51,1)$ & $22(48,9)$ & \\
\hline
\end{tabular}

Tabla 5

Distribución y características de los gérmenes hallados en los pacientes con bacteriuria postoperatoria

\begin{tabular}{|c|c|}
\hline Microorganismo & № de casos (\%) \\
\hline Escherichia coli & $35(35,4)$ \\
\hline Enterococcus faecalis & $22(22,2)$ \\
\hline Pseudomona aeruginosa & $9(9,1)$ \\
\hline Enterobacter cloacae & $7(7,1)$ \\
\hline Staphylococcus epidermidis & $7(7,1)$ \\
\hline Morganella morganii & $3(3,0)$ \\
\hline Citrobacter koserii & $2(2,0)$ \\
\hline Proteus mirabilis & $2(2,0)$ \\
\hline Streptococcus agalactiae & $2(2,0)$ \\
\hline Staphilococcus hominis-hominis & $2(2,0)$ \\
\hline Citrobacter freundii & $1(1,0)$ \\
\hline Streptococcus $s p$ & $1(1,0)$ \\
\hline Enterococcus durans & $1(1,0)$ \\
\hline Enterococcus faecium & $1(1,0)$ \\
\hline Klebsiella oxytoca & $1(1,0)$ \\
\hline Klebsiella pneumoniae & $1(1,0)$ \\
\hline Staphylococcus saprophiticus & $1(1,0)$ \\
\hline Staphylococcus simulans & $1(1,0)$ \\
\hline Candida $s p$ & $1(1,0)$ \\
\hline \multicolumn{2}{|l|}{ Familias bacterianas } \\
\hline Enterobacterias & $52(53,1)$ \\
\hline Estreptococos - Enterococos & $26(26,5)$ \\
\hline Estafilococos & $11\left(11^{\prime} 2\right)$ \\
\hline Pseudomonas & $9(9,2)$ \\
\hline \multicolumn{2}{|l|}{ Clasificación de Gram } \\
\hline Negativo & $61(62,2)$ \\
\hline Positivo & $37(37,8)$ \\
\hline \multicolumn{2}{|c|}{ Sensibilidad al antibiótico profiláctico } \\
\hline Sensible & $37(37,4)$ \\
\hline Resistente & $62(62,6)$ \\
\hline
\end{tabular}

coli, siendo éste y Enterococcus faecalis los responsables del $62,5 \%$ de las bacteriurias en el preoperatorio. Como cabría esperar, las dos terceras partes de estas bacteriurias son debidas a microorganismos gram negativos. Nos ha llamado poderosamente la atención la alta tasa de resistencias, de un 43,1\%, de estos microorganismos al tipo de antibiótico seleccionado para la profilaxis.
La tasa de infecciones tras la cirugía urológica endoscópica es muy variable según los autores, y oscila entre el 6 y el $60 \%{ }^{20}$. En nuestra serie dicha tasa fue del $22 \%$, asociándose únicamente a la presencia de bacteriuria preoperatoria. Otros trabajos relacionan la bacteriuria postoperatoria con el tiempo quirúrgico (>52 minutos), utilización de sistemas de recogida de orina abiertos y la permanencia de la sonda vesical mas de 3 $\operatorname{dias}^{21,22}$.

Se han identificado los factores de riesgo asociados con el aumento de las probabilidades de complicaciones infecciosas, incluyendo la orina infectada preoperatoriamente y la presencia de sonda vesical $^{23}$. La mayor parte de los trabajos que analizan el papel de la profilaxis antibiótica en la cirugía endoscópica descartan aquellos pacientes con cultivos de orina previos a la cirugía positi$\operatorname{vos}^{8,13-15,21,23-26}$ o portadores de son$\operatorname{das}^{13,15,26}$; no obstante ese tipo de pacientes forman un grupo importante que debe tenerse en cuenta.

El microorganismo más frecuentemente detectado en los cultivos de orina postoperatorios fue Escherichia coli, siendo este y Enterococcus faecalis los responsables del 57,6\% de las bacteriurias en el postoperatorio. Sin embargo aumenta la tasa de cultivos de Enterococcus faecalis respecto a Escherichia coli pasando a ser Pseudomona sp. el tercer microorganismo responsable de la positividad en dichos cultivos. La tasa de resistencias al tipo de antibiótico utilizado, con un $62,6 \%$, es muy superior a la de los cultivos del preoperatorio.

Existe un elevado número de trabajos publicados que analizan las complicaciones infecciosas y su relación con el uso de antibióticos profilácticos en la RTUP, pero las referencias en otras cirugías endoscópicas son escasas.

La mayor parte de los autores aceptan la administración de antibióticos profilácticos en casos de riesgo elevado, pero su uso en las poblaciones con bajo riesgo es discutible y aún pre- 
senta dudas, particularmente en el tipo del antibiótico profiláctico y en la duración del tratamiento ${ }^{27}$.

Mebust publica en 1989 los resultados sobre un estudio multicéntrico que el $40 \%$ de los urólogos americanos no dan antibióticos profilácticos en la RTUP15. Wilson realiza una encuesta a urólogos ingleses sobre sus hábitos a al hora de administrar antibióticos profilácticos a los pacientes que se iban a intervenir de RTU de próstata y que eran portadores de sonda ${ }^{28}$. El 98\% reconocen la necesidad de la profilaxis antibiótica. De los 248 encuestados no administran antibióticos en el 1,6\%, en el 45,2\% únicamente monodosis antes de la cirugia, en el $31,8 \%$ dan monodisis antes de la cirugía y en el momento de retirar la sonda y $21,4 \%$ administran antibióticos mientras los pacientes lleven sonda.

Aunque algunos autores sólo recomiendan antibióticos en pacientes de alto riesgo y sólo $\operatorname{monodosis}^{24,29}$, la tendencia actualmente es a recomendar la utilización de profilaxis antibiótica en todos aquellos que son intervenidos endoscópicamente de patología prostática. Con ello no sólo se observa un descenso en la tasa de bacteriuria en el postoperatorio, sino que también desciende la tasa de morbimortalidad relacionada con la septicemia ${ }^{30,31}$

Berry, en una revisión con un total de 4.260 sujetos intervenidos de RTUP, observó la presencia de bacteriuria postoperatoria en el $9,1 \%$ de los pacientes que reciben profilaxis frente al $26 \%$ de los que no la reciben. La tasa de septicemia descendió del $7 \%$ al $4,4 \%{ }^{12}$.

La duración del tratamiento antibiótico es otro punto de controversia. Hay autores que recomiendan únicamente monodosis ${ }^{3,7-8,20}$, otros apuestan por una pauta corta ${ }^{9-13}$ mientras que otros utilizan pautas de antibióticos largas ${ }^{14,15}$. Grabe $^{23}$ observa una reducción del 35 al 10\% de bacteriurias postoperatorias manteniendo el antibiótico hasta 5 días después de retirar la sonda al compararlo con el mismo antibiótico hasta la retirada de la sonda. Ambos regímenes eran mejores que la no utilización de antibióti$\cos (82 \%$ bacteriuria postoperatoria). También hay estudios que recomiendan la utilización de antibióticos previos a la retirada de la sonda vesical $^{32}$.
Morris $^{33}$ argumenta que la causa de las infecciones urinarias se debe a las bacterias alojadas en la próstata y que se liberan al tracto urinario durante la cirugía. Nielsen ${ }^{14}$ sugiere que las bacteriurias postoperatorias tras una RTUP son debidas a la acumulación de bacterias en la próstata o bien en algunos casos podrían ser debidas a bacterias que acceden a la orina a través de la sonda vesical. Por ello dan antibióticos hasta retirada de sonda. Goldwasser ${ }^{34}$ afirma que la fuente de dichas infecciones, no sólo en las RTUP sino también en las RTU de tumores vesicales, provienen en la mayoría de los casos de las manipulaciones perioperatorias y no del tejido resecado. No obstante, la orina parece ser el principal vector para el paso de microorganismos a la sangre, dada la coincidencia en cuanto al microorganismo en los hemocultivos y urinocultivos en la mayor parte de los casos ${ }^{33}$.

En cuanto al antibiótico utilizado existe mucha variabilidad. La elección del antibiótico depende de la sensibilidad bacteriana local y de los patrones de resistencia ${ }^{17}$. Las bacteriurias aisladas suelen ser debidas a bacterias gram positivas mientras que las producidas por gram negativas se asocian a mayor afectación sistémica. Es recomendable elegir antibióticos que cubran microorganismos gram negativos ${ }^{21,35}$.

Slavis ${ }^{25}$ utilizó cefonicid $1 \mathrm{~g}$ por vía intramuscular por su bajo costo, elevada vida media y espectro apropiado. Muchos autores recomiendan ciprofloxacino ${ }^{23,36-38}$, aunque la Food and Drug Administration recomienda las cefalosporinas de tercera generación ${ }^{39}$.

Nosotros utilizamos al principio del estudio como antibiótico profiláctico la cefazolina por ser el antibiótico recomendado por el Comité de Infecciones de nuestro hospital. Sin embargo, tras realizar un análisis precoz de los resulta$\operatorname{dos}^{40}$, cambiamos a amoxicina/clavulánico por parecernos el más apropiado con los datos bacteriológicos con los que contábamos hasta la fecha. Un reducido número de pacientes recibieron ciprofloxacino por ser alérgicos a la penicilina o bien por preferencias del cirujano.

Hay pocas referencias sobre la necesidad de profilaxis antibiótica en las resecciones de tumores vesicales. Delavierre ${ }^{41}$ concluye que no es necesaria, aunque todos sus pacientes tenían 
cultivos preoperatorios negativos. Upton ${ }^{42}$ llega previamente a la misma conclusión utilizando un antibiótico poco habitual en la profilaxis quirúrgica, la carbenicilina. Tres años antes se publicó una comparación entre la tasa de bacteriurias en un grupo de pacientes intervenidos de RTU de tumor vesical y otro grupo intervenido de RTUP. Ninguno recibió antibióticos profilácticos y descartaron aquellos pacientes con cultivos preoperatorios positivos. Observaron una tasa de bacteriurias postoperatorias del $19,4 \%$ y del $32 \%$, respectivamente. Dichas diferencias las achacaron a las manipulaciones perioperatorias ${ }^{34}$.

De los 345 pacientes, $10(2,9 \%)$ tuvieron criterios de sepsis de origen urinario durante la estancia hospitalaria y $7(2 \%)$ en el período comprendido entre el alta hospitalaria y la primera visita postoperatoria. Un paciente presentó estos criterios tanto durante el ingreso como tras el alta hospitalaria.

La sepsis se asoció únicamente a la duración de la cirugía y no, como cabría esperar, a la presencia de bacteriuria preoperatoria ni a la utilización, en estos casos, de un antibiótico profiláctico "no apropiado".

El antibiótico profiláctico ideal sería aquel que cubriera la mayor parte de los microorganismos detectados en nuestro estudio, que fuera especialmente activo frente a microorganismos gram negativos, con efectos secundarios tolerables, que se eliminara especialmente por orina, que pudiera ser administrado por vía parenteral y vía oral, que no estuviera reservado para situaciones infecciosas especiales y de bajo coste económico. Teniendo en cuenta estas premisas y basándonos en los datos obtenidos de los cultivos de orina tanto preoperatorios como postoperatorios, decidimos seguir utilizando como antibiótico profiláctico amoxicilina/clavulánico a la dosis descrita hasta la retirada de la sonda. A los pacientes alérgicos a la penicilina consideramos como más apropiada la fosfomicina. Ante las elevadas tasas de sensibilidad de este ultimo antibiótico frente a los microorganismos detectados, al menos "in vitro", nos planteamos realizar nuevos estudios para averiguar la efectividad de la fosfomicina en la práctica clínica como antibiótico profiláctico en la cirugía endoscópica.
Dado que la incidencia de bacteriuria postoperatoria y de sepsis urinaria en el postoperatorio se asocia de forma importante con la bacteriuria preoperatoria, sería de gran utilidad obtener un cultivo de orina antes de someter a los pacientes a este tipo de intervenciones.

\section{CONCLUSIÓN}

Nuestra tasa de bacteriuria preoperatoria fue del $15,4 \%$. Los cultivos de orina realizados en el preoperatorio estaban relacionados de forma significativa con la edad, el sexo, la existencia de infecciones de orina previas, la presencia de diabetes mellitus, el tipo de patología que indicaba la cirugía y la presencia de sonda vesical antes de la misma.

Los microorganismos mas frecuentemente detectados fueron Escherichia coli y Enterococcus faecalis. Nos ha llamado poderosamente la atención la alta tasa de resistencias de estos microorganismos al tipo de antibiótico seleccionado para la profilaxis.

La tasa de bacteriuria postoperatoria, con un $22 \%$, se asocia únicamente a la presencia de bacteriuria preoperatoria.

La sepsis se asoció únicamente a la duración de la cirugía y no, como cabría esperar, a la presencia de bacteriuria preoperatoria ni a la utilización, en estos casos, de un antibiótico profiláctico "no apropiado".

Basándonos en los datos obtenidos de los cultivos de orina tanto preoperatorios como postoperatorios, decidimos seguir utilizando como antibiótico profiláctico amoxicilina/clavulánico a la dosis descrita hasta la retirada de la sonda. A los pacientes alérgicos a la penicilina consideramos como más apropiada la fosfomicina.

Dada la alta incidencia de bacteriuria antes de la intervención quirúrgica y dado que la incidencia de bacteriuria postoperatoria se asocia de forma importante con la bacteriuria preoperatoria, sería de gran utilidad obtener un cultivo de orina antes de la cirugía.

Este trabajo ha sido financiado por la Dirección General de la Agencia para la Calidad, Evaluación y Modernización de los Servicios Asistenciales (Conselleria de Sanidad de la Generalitat Valenciana) con la beca no 003/2001. 
Agradecimientos: Agradecemos a todo el personal de enfermería y auxiliar del Servicio de Urología por su estrecha colaboración durante el desarrollo de todo el proyecto y a Miguel Ángel Mora por la revisión del texto.

\section{REFERENCIAS}

1. Collado A, Chechile Ge, Salvador J, Vicente J. Early complications of endoscopic treatment for superficial bladder tumors. J Urol 2000;164(5):1529-1532.

2. Childs $\mathrm{Sj}$. Antibiotic genitourinary surgical prophylaxis. Chemioterapia 1987;(3):221-224.

3. Childs Sj. Appropriate surgical prophylaxis in transurethral genitourinary surgery and potential reduction in nosocomial infections. Urology 1986;27(5):415-420.

4. Gibbons Rp, Stark Ra, Correa Rj Jr, Cummings Kb, Mason Jt. The prophylactic use -or misuse- of antibiotics in transurethral prostatectomy. J Urol 1978;119(3):381-383.

5. Holl Wh, Rous Sn. Is antibiotic prophylaxis worthwhile in patients with transurethral resection of prostate? Urology 1982;19(1):43-46.

6. Goldwasser B, Bogokowsky B, Nativ O, Sidi Aa, Jonas P, Many M. Urinary infections following transurethral resection of bladder tumors-rate and source. J Urol 1983; 129(6): 1123-1124.

7. Scholz M, Luftenegger W, Harmuth H, Wolf D, Holtl W. Single-dose antibiotic prophylaxis in transurethral resection of the prostate: a prospective randomized trial. $\mathrm{Br} \mathrm{J}$ Urol 1998;81(6):827-829.

8. Klimberg iw, malek gh, cox ce, patterson al, whalen e, kowalsky sf, echols rm. Single-dose oral ciprofloxacin compared with cefotaxime and placebo for prophylaxis during transurethral surgery. J Antimicrob Chemother 1999; 43 (Suppl A):77-84

9. Williams M, Hole Dj, Murdoch Rw, Ogden Ac, Hargreave Tb. 48-hour cephradine and post-prostatectomy bacteriuria. $\mathrm{Br}$ J Urol 1980;52(4):311-315.

10. Hargreave $\mathrm{Tb}$, Gould Jc, Kinninmonth Aw, Jeffrey Rr, Varma Js, Macintyre Cc, Elton Ra, Chisholm Gd. A randomized trial of 48 hours of prophylactic cefotaxime versus single dose in transurethral prostatic surgery. $\mathrm{J}$ Antimicrob Chemother 1984; 14(Suppl B):263-269.

11. Madsen Po, Graversen Ph. Antimicrobial prophylaxis in transurethral surgery. Infection 1986;14(5):201-202.

12. Berry A, Barratt A. Prophylatic antibiotic use in transurethral prostatic resection: a meta-analysis. J Urol 2002;167(2 Pt 1):571-577.

13. Desai Km, Abrams Ph, White Lo. A double-blind comparative trial of short-term orally administered enoxacin in the prevention of urinary infection after elective transurethral prostatectomy: a clinical and pharmacokinetic study. J Urol 1988; 139(6):1232-1234.

14. Nielsen Os, Maigaard S, Frimodt-Moller N, Madsen Po. Prophylactic antibiotics in transurethral prostatectomy. J Urol 1981;126(1):60-62.

15. Mebust Wk, Holtgrewe Hl, Cockett At, Peters Pc. Transurethral prostatectomy: immediate and postoperative complications. A cooperative study of 13 participating institutions evaluating 3,885 patients. J Urol 1989;141(2): 243-247.

16. Melchior J, Valk WI, Foret Jd, Mebust Wk. Transurethral prostatectomy: computerized analysis of 2,223 consecutive cases. J Urol 1974;112(5):634-642.
17. Asuero Mantero M, Gómez Velázquez M, Leal Arenas J. Profilaxis antibiótica en cirugía urológica endoscópica. Actas Urol Esp 1989;13(5):353-356.

18. Elmalik Em, Ibrahim Ai, Gahli Am, Saad Ms, Bahar Ym. Risk factors in prostatectomy bleeding: preoperative urinary infection is the only reversible factor. Eur Urol 2000; 37(2): 199-204.

19. Schaeffer Aj. Comparison of single-dose antibiotic prophylaxis in uncomplicated transurethral resection of the prostate. J Urol 1992;147(5):1303-1306. Replica al autor 1306.

20. Madsen Po, Larsen Eh, Dorflinger T. The role of antibacterial prophylaxis in urologic surgery. Urology 1985;26(1 Suppl): $38-42$.

21. Hargreave Tb, Botto H, Rikken Gh, Hindmarsh Jr, Mcdermott Te, Mjolnerod Ok, Petays P, Schalkhauser K, Stellos A. European collaborative study of antibiotic prophylaxis for transurethral resection of the prostate. Eur Urol 1993; 23(4):437-443.

22. Vivien A, Lazard T, Rauss A, Laisne Mj, Bonnet F. Infection after transurethral resection of the prostate: variation among centers and correlation with a long-lasting surgical procedure. Association pour la Recherche en AnesthesieReanimation. Eur Urol 1998;33(4):365-369.

23. Grabe M, Forsgren A, Bjork T, Hellsten S. Controlled trial of a short and a prolonged course with ciprofloxacin in patients undergoing transurethral prostatic surgery. Eur $\mathrm{J}$ Clin Microbiol 1987;6(1):11-17.

24. Mcentee Gp, Mcphail S, Mulvin D, Thomson Rw. Single dose antibiotic prophylaxis in high risk patients undergoing transurethral prostatectomy. Br J Surg 1987;74(3): 192-194.

25. Slavis Sa, Miller Jb, Golji H, Dunshee Cj. Comparison of single-dose antibiotic prophylaxis in uncomplicated transurethral resection of the prostate. J Urol 1992;147(5): 1303-1306.

26. Colau A, Lucet Jc, Rufat P, Botto H, Benoit G, Jardin A. Incidence and risk factors of bacteriuria after transurethral resection of the prostate. Eur Urol 2001; 39(3):272-276.

27. Mebust Wk. Prophylactic antibiotics in transurethral surgery. J Urol 1993; 150(5 Pt 2):1734-1735.

28. Wilson Jr, Puri R, Prescott S, Urwin Gh. The catheterized patient undergoing transurethral resection of the prostate: a survey of the current practice of British urologists. BJU Int 2003;92(6):589-591.

29. Wilson Ni, Lewi Hj. Survey of antibiotic prophylaxis in British urological practice. Br J Urol 1985;57(4):478-482.

30. Platt R, Polk Bf, Murdock B, Rosner B. Mortality associated with nosocomial urinary-tract infection. N Engl J Med 1982; 307(11):6376-42.

31. Bryan Cs, Reynolds Kl. Hospital-acquired bacteremic urinary tract infection: epidemiology and outcome. J Urol 1984;132(3):494-498.

32. Ward V, Wilson J, Taylor L, Cookson B, Glynn A. Preventing hospital-acquired infection: clinical guidelines. London: Public Health Laboratory Service, 1997.

33. Morris Mj, Golovsky D, Guinness Md, Maher Po. The value of prophylactic antibiotics in transurethral prostatic resection: a controlled trial, with observations on the origin of postoperative infection. Br J Urol 1976;48(6) 479-484.

34. Goldwasser B, Bogokowsky B, Nativ O, Sidi Aa, Jonas P, Many M. Urinary infections following transurethral resection of bladder tumors-rate and source. J Urol 1983;129(6): 1123-1124. 
35. Viitanen J, Talja M, Jussila E, Nurmi M, Permi J, Puolakka Vm, Rintala E, Salmela H, Tiitinen J, Tuhkanen K. Randomized controlled study of chemoprophylaxis in transurethral prostatectomy. J Urol 1993;150(5 Pt 2): 17151717.

36. Dan M, Golomb J, Gorea A, Braf Z, Berger Sa Concentration of ciprofloxacin in human prostatic tissue after oral administration. Antimicrob Agents Chemother 1986;30(1):88-89.

37. Grabe M, Forsgren A, Bjork T. Concentrations of ciprofloxacin in serum and prostatic tissue in patients undergoing transurethral resection. Eur $\mathrm{J}$ Clin Microbiol 1986;5(2):211-212.

38. Naber Kg, Sorgel F, Kinzig M, Weigel Dm. Penetration of ciprofloxacin into prostatic fluid, ejaculate and seminal fluid in volunteers after an oral dose of $750 \mathrm{mg}$. J Urol 1993;150(5 Pt 2):1718-1721.

39. Food And Drug Administration. Summary basis for approval for cefotaxime NDA 50-547. 1994. FDA, Washington, DC. (C28)
40. Menéndez V, Galán Ja, De Nova E, Elía M, Collado A, Lloréns Fj, García F. Estudio bacteriológico de la orina previo a la cirugía endoscópica. XXV Congreso de la Asociación Murciana de Urología y Asociación de Urología de la Comunidad Valenciana. 2001.

41. Delavierre D, Huiban B, Fournier G, Le Gall G, Tande D, Mangin P. Intérêt de l'antibioprophylaxie au cours des résections trans-urètrales de tumeurs de vessie. À propos de 61 cas. Prog Urol 1993;3(4):5775-82.

42. Upton Jd, Das S. Prophylactic antibiotics in transurethral resection of bladder tumors: are they necessary? Urology 1986;27(5):421-423.

Dra. V. Menéndez López

Servicio de Urología. Hospital General Univ. de Elche Camí de l'Almàssera, 11 - 03203 Elche (Alicante) E-mail: violetamenendez@wanadoo.es

(Trabajo recibido el 29 julio 2005) 